\title{
Effect of Four Mycorrhizal Products on Fusarium Root Rot on Different Vegetable Crops
}

\section{Al-Hmoud G* and Al-Momany A}

University of Jordan, Faculty of agriculture, Department of Plant Protection, Amman, Jordan

\begin{abstract}
Vesicular arbuscular mycorrhizal fungi (VAM) are symbiotic fungi which interact with the root system of higher plants by producing external and internal hyphae, vesicules and arbuscules. This study aimed to determine the efficiency of different vesicular arbuscular mycorrhizal fungi in improving plant resistance against Fusarium oxysporum. Four mycorrhizal products; Bacto_Prof, Endomyk_Basic, Endomyk_Conc and Endomyk_Prof were used. Glomus intraradices was the mycorrhizal fungus. All products reduced Fusarium infection by increasing the plant height and reducing the root infection. Bacto_Prof was the best product in the presence of Fusarium infection of tomato plants which showed an increase in plant height up to $44 \%$ and $154 \%$ in plant fresh root weight (FRW). Fusarium was reduced by $50 \%$ in Bacto_Prof treated tomato plants and mycorrhizal colonization was enhanced from $31 \%$ to $42 \%$ in Fusarium infected tomato seedlings. In pepper experiment; Endomyk_Basic was the best product in all treatments which enhanced mycorrhizal root colonization from $56 \%$ to $68 \%$. Fusarium infection was suppressed in pepper treated plants with Endomyk. Basic from 2.45\% to 1.5\%. Mycorrhizal colonization with all products was enhanced by the presence of Fusarium more than in non-infected plants. In squash experiment Endomyk_Basic was the best product, but in root colonization Endomyk_Conc performed the best form $52 \%$ to $64 \%$. From the results of this study, it was concluded that all mycorrhizal products were significantly inhibited Fusarium infection by enhanced and increased mycorrhizal root colonization, so enhanced plant growth and increased root volume.
\end{abstract}

Keywords: Symbiotic fungi; Mycorrhizal fungi; Glomus intraradices; Fusarium

\section{Introduction}

Mycorrhiza is a symbiotic association between a fungus and the root system of vascular plants belonging to phylum Glomeromycota [1,2] (www. Mycobank.org). Symbiosis, the mutual beneficial association. Mycorrhizal fungi are the most widespread fungal symbionts that colonizes root system of over $90 \%$ of plant species to the mutual benefit of both the plant host and fungus [3,4] either exteracellularly as in ectomycorrhizal fungi or intercellularly as in endomycorrhizal fungi [arbuscular mycorrhizal (AM) fungi]. Vesicular arbuscular mycorrhiza (VAM) colonizes plant roots and extends into the surrounding bulk soil to the root depletion zone around the root system [5]. Different crops exhibited different VAM species and different stages of fungal invasion ranging from hyphae, arbuscules and vesicles or combinations of all structures [6]. The major role of VA-fungi is to supply plant roots with phosphorus, because phosphorus is an extremely immobile element in soils [7]. A Vesicular-arbuscular mycorrhiza (VAM) fungus was first studied in Jordan by Dr. Al-Momany in 1993 [6].

However, the mutualistic symbiosis between arbuscular mycorrhizal fungi (AMF) and plant roots plays an important role in nutrient cycling in the ecosystem and can protect plants against soil-borne pathogens [4]. Two main groups of soil-borne pathogens have been studied: nematodes and fungi such as Phytophthora spp, Verticillium wilt and Fusarium wilt. In the presence of arbuscular mycorrhizal fungi (AMF), a reduction in pathogen population or in the disease severity on the host plant has been demonstrated [8]. Also, AMF protect unsupervised root from parasitic fungi by increase wall thickness in the cortical cells of the roots [9]. However, the efficacy of AMF as disease control agents depends on several abiotic and biotic factors, such as temperature, soil moisture, soil phosphorus content, mycorrhizal fungus, time of mycorrhizal inoculation, levels of mycorrhizal inoculum, and inoculum potential of pathogen [4].

The soil born pathogen Fusarium oxysporum infect the vascular system of vegetable crops severely especially in hot weather such as in Jordan Valley. F. oxysporum can persist in soil for long period of time as chlamydospores which enters the root system through wounds. The first symptoms appear as slight vein clearing on the outer younger leaflets, on older leaves epinasty caused by drooping of the petioles, followed by stunting of the plants, after that yellowing of the lower leaves and wilting of the whole plant then death occur.

Therefore, this work was conducted to determine the effect of mycorrhizal products in its recommended dose on the performance of infected tomato, pepper, squash and eggplant plants with Fusarium oxysporum.

\section{Materials and Methods}

\section{Mycorrhizal products and Fusarium culture}

Four different mycorrhizal products were exported from Terrabioscience UG. Bernbug-Germany; and each product was used in different doses according to the application rates and instructions indicated by the manufacturer; Bacto_Prof (1 g/L soil), Endomyk Conc ( $1 \mathrm{~g} / \mathrm{L}$ soil), Endomyk_Prof ( $2 \mathrm{~g} / \mathrm{L}$ soil) and Endomyk_Basic ( 8 $\mathrm{g} / \mathrm{L}$ soil). All the mycorrhizal products were in powder form except Endomyk_Basic, the mycorrhizae was produced in granule form.

*Corresponding author: Al-Hmoud G, University of Jordan, Faculty of agriculture Department of Plant Protection, Amman, Jordan, Tel: 9626535 5000; E-mail: Aeng_ghina2009@yahoo.com, momanyah@ju.edu.jo

Received January 11, 2015; Accepted January 20, 2015; Published January 25 2015

Citation: Al-Hmoud G, Al-Momany A (2015) Effect of Four Mycorrhizal Products on Fusarium Root Rot on Different Vegetable Crops. J Plant Pathol Microb 6: 255. doi:10.4172/2157-7471.1000255

Copyright: @ 2015 Al-Hmoud G, et al. This is an open-access article distributed under the terms of the Creative Commons Attribution License, which permits unrestricted use, distribution, and reproduction in any medium, provided the original author and source are credited. 
Fusarium oxysporum f.sp. lycopersici was isolated from infested field soil planted with tomato, and Fusarium oxysporum f.sp. cucumerinum was isolated from infected field soil planted with cucumber in 2011 in Jordan Valley. Fusarium oxysporum f.sp. lycopersici was used to inoculate tomato, pepper and eggplant seedlings. While Fusarium oxysporum f.sp. cucumerinum was used for inoculate squash seedlings.

\section{Glasshouse work}

The effect of the four mycorrhizal products on Fusarium wilt (Fusarium oxysporum) was studied on different vegetable crops; tomato (Solanum lycopersicum) var. Majd, eggplant (Solanum melongena) var. Ajami, pepper (Capsicum frutescens) var. Hendi, and squash (Cucurbita maxima) var. Yasmina F1. The seedlings must be under drought conditions before using them. The Fusarium suspension was prepared in the same day of inoculation for the viability of micro and macro conidia. Seedlings were cleaned from peat moss around the root system to facilitate inoculation. Fusarium inoculum; PDA plates containing Fusarium growth were transferred to blender, mixed with distilled water for two minutes. The inoculum contained micro and macro conidia and mycelium. The concentration of Fusarium was determined by using a haemacytometer slide. $10^{9} \mathrm{spores} / \mathrm{ml}$ was made to inoculate tomato, pepper and eggplant seedlings and $10^{6}$ spores $/ \mathrm{ml}$ used for squash seedlings. For each seedling, $50 \mathrm{ml}$ of inoculum were added to the root zone of the four-week old mycorrhizal seedlings of tomato, pepper, eggplant and two-week old mycorrhizal seedlings of squash by pouring the suspension into a hole made around the root zone.

At the same time soil: sand mixture was treated with the normal recommended dose for each product to plant one seedling in each sterilized pot. For each crop, ten treatments were used; four products with Fusarium, four products without Fusarium, Fusarium alone and non-inoculated plants (control). For treatments using mycorrhizal products with Fusarium; half amount of the soil: sand: product mixture was transferred to the pot, then each seedling was dipped in $50 \mathrm{ml}$ Fusarium suspension for two minutes and then add the rest of the suspension to the root zone, then completed the rest of the soil mixture. Each treatment was comprised of five replicate pots, grown under glasshouse conditions until harvest time (7-8 weeks). At the end of the experiment plants were taken to test them for Fusarial infectivity. Shoot length was measured; fresh shoot weight (FSW) and fresh root weights (FRW) were recorded. One gram of fine feeder roots from each treatment were taken to examine its mycorrhizal colonization, then put the fresh shoot and root of each treatment in separate closed paper bags, and dried for $24 \mathrm{hrs}$ at $70^{\circ} \mathrm{C}$ in the oven to measure the dry shoot weight (DSW). All data were statistically analyzed by using the SAS program, comparison between means was done according to LSD at $5 \%$ level.

\section{Evaluation of the experiment}

Inoculation of mycorrhizal seedlings with Fusarium oxysporum: Fresh infected seedlings with Fusarium were examined from the crown area (creamy to brown color), cleaned by tap water from soil, cut to pieces, sterilized by $0.5 \%$ hypex, dried on sterilized filter paper and then four pieces were placed $(2 \times 2 \mathrm{~cm})$ on potato dextrose agar (PDA) plates $(39 \mathrm{gm} / \mathrm{l})$, then kept for two weeks in the incubator at $25^{\circ} \mathrm{C} \pm 2{ }^{\circ} \mathrm{C} . \mathrm{F}$. oxysporum f.sp. cucumerinum needs higher incubation temperature than F. oxysporum f.sp. lycopersici; about $27-28^{\circ} \mathrm{C}$. Fusarium growth appeared in different colors (white, pink, purple and sometimes yellow in F. oxysporum f.sp. cucumerinum). To make sure if it is Fusarium; microscopic slides from those different colors were prepared under the microscope. Micro and macro conidia ranging from one cell to four or five conidial cells were seen in huge numbers. Then pure inoculum of Fusarium was prepared using sterilized cork borer. In each PDA plate one or two Fusarium discs were placed, and plates were incubated for another two weeks at $24-26^{\circ} \mathrm{C} \pm 2^{\circ} \mathrm{C}$.

Evaluation of Fusarium infection: At the end of glasshouse experiments, plants were taken to the laboratory to re-isolate Fusarium on PDA plates to ensure the Fusarium infection. Above the crown area by $2 \mathrm{~cm}$, small pieces $(1 \times 1 \mathrm{~cm})$ were cut, washed by tap water, sterilized by $0.5 \%$ hypex, dried on sterilized filter paper and then placed four pieces in each plate. The plates were incubated at $25^{\circ} \mathrm{C}$ for $5-7$ days. After the incubation period, infected pieces were counted and examined microscopically in each petridish to ensure the Fusarium infection.

Evaluation of VAM roots colonization: Roots were washed carefully to remove soil particles, then heated in $10 \% \mathrm{KOH}$ at $90^{\circ} \mathrm{C}$ for half an hour to destroy cell cytoplasm, so the plant cell will be cleared, then washed for 2-3 minutes in running tap water gently, then stained with $0.05 \%$ trypan blue in lactophenol according to Philips and Hayman method (1970). Ten root segments with $1 \mathrm{~cm}$ length were mounted on each slide and examined microscopically. The incidence and intensity of root colonization with mycorrhiza were calculated using a scale of (0-10) where zero means no colonization, 5 means $50 \%$ mycorrhizal root colonization and 10 means $100 \%$ mycorrhizal root colonization [10], the readings were taken from the average percentage of thirty roots for each treatment.

\section{Results}

\section{Tomato experiment}

Effect of Fusarium oxysporum on tomato growth was presented in Table 1. There were no significant differences between plants inoculated with Fusarium and not inoculated with Fusarium; except in Fusarium severity. However; considering plant height parameters, Bacto_Prof was highly significant than all other products by $44 \%$, and all mycorrhizal products were significantly higher than control plants by 29, 31 and 26\% in Endomyk_Basic, Endomyk_Conc and Endomyk Prof, respectively. The increase in plant FSW was 27, 23, 20 and 19\% for the four products; Bacto_Prof, Endomyk_Basic, Endomyk_Conc and Endomyk_Prof in Fusarium treatments, respectively. However, the increase in plant FRW was enhanced more in mycorrhizal plants than in non-mycorrhizal plants by $154 \%$ for Bacto_Prof and Endomyk Basic, while in Endomyk_Conc and Endomyk_Prof the increase was $134 \%$. Infection percentage in non-mycorrhizal plants was the highest by $8 \%$ compared with the mycorrhizal plants by $4 \%$ for Bacto_Prof, Endomyk_Conc and Endomyk_Prof and 5\% for Endomyk_Basic product.

\section{Pepper experiment}

Effect of Fusarium oxysporum on pepper growth was summarized in Table 2. There were significant differences in plant height in Fusarium treatments between mycorrhizal plants and non-mycorrhizal plants. Plant height of mycorrhizal plants infected with Fusarium in were improved by 20,27, 21 and 25\% by Bacto_Prof, Endomyk_Basic, Endomyk_Conc and Endomyk_Prof products, respectively. Plant FSW in Fusarium treatment with Endomyk_Basic was more significant than others by $115 \%$. Plant DSW was enhanced significantly by all mycorrhizal products; Bacto_Prof, Endomyk_Conc and Endomyk Prof by $56,102,85$ and $98 \%$, respectively compared to control plants 


\begin{tabular}{|c|c|c|c|c|c|c|c|}
\hline Treatment & F. oxysporum & Height (cm) & FSW (g) & DSW (g) & FRW (g) & Severity (cm) & Infection \% \\
\hline \multirow{2}{*}{ Bacto_Prof } & + & $51.6 \mathrm{a}$ & $10.622 \mathrm{a}$ & $1.868 a b$ & $4.904 \mathrm{a}$ & $2.1 \mathrm{a}$ & $4 \%$ \\
\hline & - & $50.2 a b$ & $10.162 a b$ & $1.734 a b$ & $4.678 \mathrm{a}$ & $0 \mathrm{~b}$ & 0 \\
\hline \multirow{2}{*}{ Endomyk_Basic } & + & $46.4 \mathrm{abc}$ & $10.286 a b$ & $1.844 a b$ & $4.898 \mathrm{a}$ & $2.3 a$ & $5 \%$ \\
\hline & - & $45.4 \mathrm{bc}$ & 9.484 bc & $2.006 \mathrm{a}$ & $4.798 \mathrm{a}$ & $\mathrm{Ob}$ & 0 \\
\hline \multirow{2}{*}{ Endomyk_Conc } & + & $47.1 \mathrm{abc}$ & $10.00 \mathrm{ab}$ & $1.842 a b$ & $4.5 \mathrm{a}$ & $1.8 a$ & $4 \%$ \\
\hline & - & $42.5 \mathrm{~cd}$ & $9.734 \mathrm{bc}$ & $1.648 \mathrm{ab}$ & $4.614 \mathrm{a}$ & $\mathrm{Ob}$ & 0 \\
\hline \multirow{2}{*}{ Endomyk_Prof } & + & $45.2 \mathrm{bc}$ & $9.96 a b$ & $1.656 \mathrm{ab}$ & $4.568 \mathrm{a}$ & $2 a$ & $4 \%$ \\
\hline & - & $42 \mathrm{~cd}$ & 9.722 bc & $1.636 \mathrm{ab}$ & $4.438 \mathrm{a}$ & $\mathrm{Ob}$ & 0 \\
\hline \multirow{2}{*}{ Control } & + & $35.9 \mathrm{e}$ & $8.36 \mathrm{~d}$ & $1.146 \mathrm{c}$ & $1.932 \mathrm{~b}$ & $2.8 a$ & $8 \%$ \\
\hline & - & $39.8 \mathrm{ed}$ & $9.076 \mathrm{~cd}$ & $1.35 \mathrm{bc}$ & $2.808 \mathrm{~b}$ & $\mathrm{Ob}$ & 0 \\
\hline
\end{tabular}

Values are average of five plants, values within each column followed by the same letter are not significantly different $(P<0.05)$ according to LSD. $(+)$ means inoculated with F. oxysporum while (-) means non-inoculated with F. oxysporum.

Table 1: Effect of Fusarium oxysporum with the recommended dose of mycorrhizal products on growth of tomato plants.

\begin{tabular}{|c|c|c|c|c|c|c|c|c|}
\hline Treatment & F. oxysporum & Height (cm) & Fruit wt (g) & FSW (g) & DSW (g) & FRW (g) & Severity (cm) & Infection $\%$ \\
\hline \multirow[t]{2}{*}{ Bacto_Prof } & + & $36.1 \mathrm{~b}$ & $0.368 a$ & $9.982 \mathrm{c}$ & $1.004 a b$ & $5.586 \mathrm{~b}$ & $0.56 a$ & $1.55 \%$ \\
\hline & - & $35.5 b$ & $0.058 \mathrm{abc}$ & $9.828 \mathrm{c}$ & $1.032 \mathrm{ab}$ & $5.5 b$ & $\mathrm{Ob}$ & 0 \\
\hline \multirow[t]{2}{*}{ Endomyk_Basic } & + & $38.4 \mathrm{a}$ & $0 \mathrm{c}$ & $11.258 \mathrm{a}$ & $1.296 \mathrm{a}$ & $6.578 \mathrm{a}$ & $0.56 a$ & $1.50 \%$ \\
\hline & - & $38.5 \mathrm{a}$ & $0 \mathrm{c}$ & 11.182ab & $1.27 \mathrm{a}$ & $6.294 a b$ & $\mathrm{Ob}$ & 0 \\
\hline \multirow[t]{2}{*}{ Endomyk_Conc } & + & $36.4 \mathrm{~b}$ & $0.036 a b$ & $10.112 c$ & $1.186 a b$ & $5.958 a b$ & $0.48 a$ & $1.32 \%$ \\
\hline & - & $35.8 \mathrm{~b}$ & $0.234 a b$ & $9.994 \mathrm{c}$ & $1.118 a b$ & $5.85 a b$ & $\mathrm{Ob}$ & 0 \\
\hline \multirow[t]{2}{*}{ Endomyk_Prof } & + & $37.7 \mathrm{a}$ & $0 \mathrm{c}$ & $10.59 \mathrm{abc}$ & $1.268 \mathrm{a}$ & $6.266 \mathrm{ab}$ & $0.66 a$ & $1.75 \%$ \\
\hline & - & $36.6 \mathrm{a}$ & $0.064 \mathrm{~b}$ & $10.35 \mathrm{bc}$ & $1.262 \mathrm{a}$ & $5.846 a b$ & $\mathrm{Ob}$ & 0 \\
\hline \multirow[t]{2}{*}{ Control } & + & $30.2 \mathrm{~d}$ & $0.028 \mathrm{bc}$ & $5.234 \mathrm{e}$ & $0.642 \mathrm{c}$ & $3.936 c$ & $0.74 a$ & $2.45 \%$ \\
\hline & - & $33.6 \mathrm{c}$ & $0 \mathrm{c}$ & $7.04 \mathrm{f}$ & $0.858 \mathrm{bc}$ & $4.008 \mathrm{c}$ & $\mathrm{Ob}$ & 0 \\
\hline
\end{tabular}

Values are average of five plants, values within each column followed by the same letter are not significantly different $(P<0.05)$ according to LSD. $(+)$ means inoculated with F. oxysporum while (-) means non-inoculated with F. oxysporum.

Table 2: Effect of Fusarium oxysporum with recommended dose of mycorrhizal products on pepper growth.

infected with Fusarium. Plant FRW, was increased significantly by 42, 67, 51 and 59\% with Bacto Prof, Endomyk Conc and Endomyk Prof products, respectively. Fusarium infection percentage in pepper control plants was the highest $2.45 \%$, compared to 1.32 and $1.5 \%$ in Endomyk_Conc and Endomyk_Basic treatments, respectively.

\section{Eggplant experiment}

Effect of Fusarium oxysporum on pepper growth was presented in Table 3. There were no significant differences between plants treated with four mycorrhizal products and inoculated with Fusarium and not inoculated with Fusarium referring to height, FSW, DSW and FRW. The four products were not significantly different from each other and all were significantly different from control plants infected with Fusarium. Plant height in Fusarium treatment with mycorrhizal products were enhanced by 14\% for Bacto_Prof, 16\% for Endomyk Basic, Endomyk_Conc and Endomyk_Prof. Plant FSW in Fusarium treatment was raised $49 \%$ by Bacto_Prof and $51 \%$ by Endomyk_Basic, Endomyk_Conc and Endomyk_Prof over non-mycorrhizal plants. Fresh root weight in Fusarium treatment was increased 49, 50, 45 and 51\% by Bacto_Prof, Endomyk_Basic, Endomyk_Conc and Endomyk_ Prof, respectively. Infection percentage in control plants was the highest (5.80\%) compared with 3.50, 2.22, 3.42 and 2.72\% for Bacto_Prof, Endomyk_Basic, Endomyk_Conc and Endomyk_Prof, respectively.

\section{Squash experiment}

Effect of Fusarium oxysporum on squash growth was presented in Table 4. There were no significant differences between FSW in Fusarium inoculated mycorrhizal plants versus non-inoculated mycorrhizal plants. Plant height in Fusarium treatment with Endomyk_Basic was
24\% higher than control plants inoculated with Fusarium, followed by 8,7 and 6\%, respectively for Endomyk_Prof, Endomyk_Conc and Bacto_Prof. In Fusarium treatment, FSW was increased $13 \%$ by Bacto_Prof and Endomyk_Prof, $23 \%$ by Endomyk_Basic and $12 \%$ by Endomyk_Conc. Squash FRW in Fusarium treatment was enhanced by 69, 88, 73 and 67\% for Bacto_Prof, Endomyk_Basic, Endomyk_Conc and Endomyk_Prof, respectively compared to control plants infected with Fusarium. Infection percentage in non-mycorrhizal squash plants was the highest by $14.45 \%$ compared with $9.41,10.13,10.92$ and $11.69 \%$ for Bacto_Prof, Endomyk_Basic, Endomyk_Conc and Endomyk_Prof products, respectively.

\section{Evaluations of VAM root colonization}

Mycorrhizal root colonization was more efficient with Fusarium infection in all vegetable crops as present in Table 5 . The examination of the control plant roots and the Fusarium inoculated plants for a possible contamination with AMF was negative. In tomato, Bacto_Prof (+Fus) was the most effective product in root colonization (42\%) followed by Endomyk_Prof (+Fus) (37\%), Endomyk_Conc (+Fus) (30\%) and then Endomyk_Basic (+Fus) with 33\%. In pepper, Endomyk_Basic (+Fus) recorded the highest root colonization by $68 \%$ than other products, comparing the products with Fusarium infection and without Fusarium. It was clear that Endomyk_Prof (+Fus) performed better than other products, while in squash, Bacto_Prof (+Fus) was more efficient than other products by $65 \%$ followed by Endomyk_Conc (+Fus) (64\%), Endomyk_Basic (+Fus) (60\%) and Endomyk_Prof (+Fus) was less effective by $55 \%$. However; Endomyk_Basic (+Fus) record the highest root colonization by $54 \%$ in eggplant, but Endomyk_Conc performed better than other products with Fusarium infection. 


\begin{tabular}{|c|c|c|c|c|c|c|c|}
\hline Treatment & F. oxysporum & Height (cm) & FSW (g) & DSW (g) & FRW (g) & Severity (cm) & Infection \% \\
\hline \multirow[t]{2}{*}{ Bacto_Prof } & + & $34.6 \mathrm{ab}$ & $9.356 \mathrm{a}$ & $1.098 a b$ & $4.866 \mathrm{a}$ & $1.2 \mathrm{a}$ & $3.50 \%$ \\
\hline & - & $35.9 \mathrm{a}$ & $9.916 \mathrm{a}$ & $1.192 \mathrm{a}$ & $4.726 \mathrm{a}$ & $0 \mathrm{c}$ & 0 \\
\hline \multirow[t]{2}{*}{ Endomyk_Basic } & + & $35.1 \mathrm{a}$ & 9.464 a & $1.07 \mathrm{ab}$ & $4.924 \mathrm{a}$ & $0.78 \mathrm{a}$ & $2.22 \%$ \\
\hline & - & $35.3 \mathrm{a}$ & $9.61 \mathrm{a}$ & $1.054 \mathrm{abc}$ & $4.922 \mathrm{a}$ & $0 \mathrm{c}$ & 0 \\
\hline \multirow[t]{2}{*}{ Endomyk_Conc } & + & $35.1 \mathrm{a}$ & $9.45 \mathrm{a}$ & $1.106 a b$ & $4.738 \mathrm{a}$ & $1.2 \mathrm{a}$ & $3.42 \%$ \\
\hline & - & $35.4 \mathrm{a}$ & $9.478 \mathrm{a}$ & $1.152 \mathrm{a}$ & $4.8 \mathrm{a}$ & $0 \mathrm{c}$ & 0 \\
\hline \multirow[t]{2}{*}{ Endomyk_Prof } & + & $35.2 \mathrm{a}$ & $9.434 \mathrm{a}$ & $1.128 \mathrm{a}$ & $4.952 \mathrm{a}$ & $0.96 \mathrm{a}$ & $2.72 \%$ \\
\hline & - & $35.1 \mathrm{a}$ & $9.454 \mathrm{a}$ & $1.13 \mathrm{a}$ & $4.906 \mathrm{a}$ & $0 \mathrm{c}$ & 0 \\
\hline \multirow[t]{2}{*}{ Control } & + & $30.4 \mathrm{c}$ & $6.264 \mathrm{~b}$ & $0.866 \mathrm{c}$ & $3.276 \mathrm{~b}$ & $1.76 \mathrm{~b}$ & $5.80 \%$ \\
\hline & - & $32.4 \mathrm{bc}$ & $7.014 \mathrm{~b}$ & 0.922 bc & $4.224 a b$ & $0 \mathrm{c}$ & 0 \\
\hline
\end{tabular}

Values are average of five plants, values within each column followed by the same letter are not significantly different $(P<0.05)$ according to LSD. $(+)$ means inoculated with F. oxysporum while (-) means non-inoculated with F. oxysporum.

Table 3: Effect of Fusarium oxysporum with recommended dose of mycorrhizal products on growth of eggplant.

\begin{tabular}{|c|c|c|c|c|c|c|c|}
\hline Treatment & F. oxysporum & Height (cm) & FSW (g) & DSW (g) & FRW (g) & Severity $(\mathrm{cm})$ & Infection $\%$ \\
\hline \multirow[t]{2}{*}{ Bacto_Prof } & + & $45.7 \mathrm{bc}$ & $13.404 a b$ & $3.506 \mathrm{a}$ & $4.534 \mathrm{a}$ & $4.3 a$ & $9.41 \%$ \\
\hline & - & $48.2 \mathrm{bc}$ & $13.792 a b$ & $3.476 \mathrm{a}$ & $4.568 \mathrm{a}$ & $0 c$ & 0 \\
\hline \multirow[t]{2}{*}{ Endomyk_Basic } & + & $53.3 \mathrm{a}$ & $14.562 \mathrm{a}$ & $3.406 \mathrm{a}$ & $5.038 \mathrm{a}$ & $5.4 a$ & $10.13 \%$ \\
\hline & - & $49 a$ & $13.876 \mathrm{a}$ & $2.988 \mathrm{a}$ & $4.832 \mathrm{a}$ & $0 c$ & 0 \\
\hline \multirow[t]{2}{*}{ Endomyk_Conc } & + & $45.8 \mathrm{abc}$ & $13.44 a b$ & $3.284 \mathrm{a}$ & $4.656 \mathrm{a}$ & $5 a$ & $10.92 \%$ \\
\hline & - & $49.4 a b$ & $13.874 \mathrm{a}$ & $3.55 \mathrm{a}$ & $4.9 \mathrm{a}$ & 0c & 0 \\
\hline \multirow[t]{2}{*}{ Endomyk_Prof } & + & $46.2 \mathrm{bc}$ & $13.314 a b$ & $3.196 \mathrm{a}$ & $4.484 \mathrm{ab}$ & $5.4 a$ & $11.69 \%$ \\
\hline & - & $49.2 a b$ & $13.87 \mathrm{a}$ & $3.102 \mathrm{a}$ & $5.05 a$ & $0 c$ & 0 \\
\hline \multirow[t]{2}{*}{ Control } & + & $42.9 \mathrm{~cd}$ & $11.882 \mathrm{c}$ & $3.43 \mathrm{a}$ & $2.684 \mathrm{~b}$ & $6.2 b$ & $14.45 \%$ \\
\hline & - & $45.6 \mathrm{~d}$ & $12.476 \mathrm{bc}$ & $3.486 \mathrm{a}$ & $3.594 \mathrm{~b}$ & $0 c$ & 0 \\
\hline
\end{tabular}

Values are average of five plants, values within each column followed by the same letter are not significantly different $(P<0.05)$ according to LSD. $(+)$ means inoculated with F. oxysporum while (-) means non-inoculated with F. oxysporum.

Table 4: Effect of Fusarium oxysporum with the recommended dose of mycorrhizal products on squash growth.

\begin{tabular}{|c|c|c|c|c|c|}
\hline Treatment & Infection & Tomato & Pepper & Squash & Eggplant \\
\hline \multirow{2}{*}{ Bacto_Prof } & + Fus & $42 \%$ & $46 \%$ & $65 \%$ & $39 \%$ \\
\hline & - Fus & $31 \%$ & $37 \%$ & $52 \%$ & $35 \%$ \\
\hline \multirow[t]{2}{*}{ Endomyk_Basic } & + Fus & $33 \%$ & $68 \%$ & $60 \%$ & $54 \%$ \\
\hline & - Fus & $30 \%$ & $56 \%$ & $54 \%$ & $50 \%$ \\
\hline \multirow[t]{2}{*}{ Endomyk_Conc } & + Fus & $30 \%$ & $53 \%$ & $64 \%$ & $51 \%$ \\
\hline & - Fus & $25 \%$ & $45 \%$ & $52 \%$ & $38 \%$ \\
\hline \multirow[t]{2}{*}{ Endomyk_Prof } & + Fus & $37 \%$ & $62 \%$ & $55 \%$ & $49 \%$ \\
\hline & - Fus & $28 \%$ & $49 \%$ & $51 \%$ & $43 \%$ \\
\hline
\end{tabular}

(+ Fus) means inoculated with F. oxysporum while (- Fus) means non-inoculated with F. oxysporum.

Table 5: Effect of Fusarium infection on mycorrhizal root colonization of different products in different vegetable crops.

\section{Discussion}

All products reduced Fusarium infection by increasing the plant height and reducing the root percentage of infected plants. The competition for space and nutrients can change the morphology of root system, rhizosphere effect and the activation of plant defense mechanisms which are responsible for disease inhibition by VAM fungi [11]. Bacto_Prof recorded the highest in all parameters than other products with $42 \%$ root colonization in tomato experiment. Microconidia of Fusarium wilt, has been shown to be stimulated by tomato root exudates, but when colonized by AMF; it was clear that root exudates of plants inhibited the germination of Fusarium microconidia more than root exudates of non-mycorrhizal plants [12]. In pepper experiment; Endomyk_Basic was the most effective, but in VAM root colonization, Endomyk_Prof was the first place by $72 \%$ then Endomyk_Basic by $68 \%$. Also Endomyk_Basic was the most effective product on both squash and eggplant.
Plant height, shoot fresh weight, shoot dry weight and root fresh weight were significantly different in mycorrhizal than nonmycorrhizal plants in all products, while number of plant flowers number, fruit number and fruit weight there, were no differences between mycorrhizal and non-mycorrhizal plants. Glomus intraradices increased plant yield, height and shoot fresh weight. However; pepper plants showed the least yield and height in comparison to tomato and eggplant [13], while in this experiment tomato showed more increase in height compared to pepper and eggplant, but pepper showed the highest mycorrhizal root colonization. The mycorrhizal tomato and eggplant plants had shown an increase in fresh, dry weight and mean plant height compared to non-mycorrhizal which was in agreement with the findings of Kargiannidis et al. [14]. Leaf area, shoot and root dry matter yields were higher in mycorrhizal tomato plants than in non-mycorrhizal [15]. Shoot weight of mycorrhizal tomato treated with or without $F$. oxysporum were more than non-mycorrhizal plants with Fusarium [9]. 
VAM can influence diseases caused by soil-borne pathogens affecting the root system. In general, mycorrhizal plants suffer less damage and the pathogen development will be inhibited $[16,17]$. Fusarium oxysporum is a soil-borne pathogen causing wilting in the vascular system of higher plants and severe yield losses for farmers. Management of Fusarium wilt is mainly through chemical soil fumigation (particularly methyl bromide) and resistant cultivars are the most cost-effective and environmentally safe methods of control. However, new races of pathogens overcoming host resistance can develop. The difficulty in controlling Fusarium wilt has stimulated the researches in biological control by micro-organisms such as arbuscular mycorrhizal fungi that are important members in the rhizosphere and considered as effective symbionts by protecting the plants from root rot pathogens. The arbuscular mycorrhizal fungi increase plant growth and enhanced plant tolerance to various stress factors. AMF may limit fungal root diseases by strengthening morphological traits of plants with some physiological and microbial modifications in the rhizosphere and by altering the chemical composition of plant tissues [11].

As soon as the VAM colonizes the plant roots the pathogen will be excluded. As a result, the most effective control is achieved when AMF colonization takes place before the pathogen attack the host cells. There are many factors involved in as; changes in root exudates which can cause changes in the rhizosphere microbial community, changes to root biochemistry connected with plant defense mechanisms. Changes to plant defense mechanisms, in another words induced resistance, resulted from a priming effect of the VAM colonization to respond faster to infection by pathogenic fungi [2].

There were no significant differences between mycorrhizal plants inoculated with Fusarium oxysporum and mycorrhizal plants alone, and this may be according to some reasons; as early planting date, delated the entrance of Fusarium, temperature or plant cultivar. The efficiency of VAM fungi can be influenced by plant pathogen, symbiotic fungi and environmental conditions [9]. While there were differences between mycorrhizal plants inoculated with $F$. oxysporum and plants inoculated with $F$. oxysporum alone. Pepper plants inoculated with $F$. oxysporum was not significantly different from plants inoculated with both VAM fungi and F. oxysporum. Mycorrhizal pepper and tomato plants inoculated with $F$. oxysporum showed higher fresh weight and plant height than plants inoculated with $F$. oxysporum only. Fusarium was more severe in non-mycorrhizal than in mycorrhizal tomato and pepper plants [16]. Pre-inoculation with VAM fungi was effective in delaying root infection with Fusarium [9].

The root colonization by the mycorrhizal products was not affected by the presence of Fusarium infection; the percentage of root colonization was higher in Fusarium infection in all examined plants. The number of Fusarium propagules was decreased significantly when plants were inoculated with Glomus intraradices and decreased root necrosis caused by Fusarium $[18,19]$. All mycorrhizal products were effective and significantly different than non-treated plants, and all mycorrhizal products were significantly inhibited Fusarium infection by enhanced the plant growth and increased root volume. Bacto_Prof increase plant growth and reduced Fusarium infection in tomato, while Endomyk_Basic was more efficient in pepper, squash and eggplant.

\section{References}

1. Kirk PM, Cannon PF, David JC, Stalpers J (2001) Ainsworth and Bisby's Dictionary of the Fungi (9thedn). Wallingford UK CAB International.

2. Gosling P, Hodge A, Goodlass G, Bending GD (2006) Arbuscular mycorrhizal fungi and organic farming. Agriculture, Ecosystems and Environment 113: 1735 .

3. Smith SE, Read DJ (1997) Mycorrhizal Symbiosis (2ndedn). Academic Press London.

4. Garmendia I, Goicoechea N, Aguirreolea J (2004) Effectiveness of three Glomus species in protecting pepper (Capsicum annuum L.) against verticillium wilt. Biological Control 31: 296-305

5. Bethlenfalvay GJ, Barea JM (1994) Mycorrhizae in sustainable agriculture Effects on seed yield and soil aggregation. American Journal of Alternative Agriculture 9: 157-161.

6. Al Raddad, Al Momany A (1993) Distribution of different Glomus species in rainfed areas in Jordan. Dirasat 20: 165-182

7. Wetterauerr DG, Killorn RJ (1996) Fallow- and flooded-soil syndromes: effects on crop production. Journal of Production Agriculture 9: 39-41.

8. Caron M (1989) Potential use of mycorrhizal in control of soil-born diseases Canadian Journal of Plant Pathology 11: 177-179.

9. Al Ameiri NS (1987) Interaction between vesicular arbuscular mycorrhizal fung and Fusarium root rot of tomato. Master dissertation University of Jordan, Amman, Jordan.

10. Bierman B, Linderman R (1981) Quantifying vesicular-arbuscular mycorrhizae: proposed method towards standardization. New Phytologist Journal 87: 63-67.

11. Akkopru A, Demir S (2005) Biological Control of Fusarium Wilt in Tomato Caused by Fusarium oxysporum $\mathrm{f}$ sp lycopersici by AMF Glomus intraradices and some Rhizobacteria. Journal of Phytopathology 153: 544-550.

12. Steinkellner S, Hage-Ahmed K, Garcia-Garrido JM, Illana A, Ocampo JA (2012). A comparison of wild-type, old and modern tomato cultivars in the interaction with the arbuscular mycorrhizal fungus Glomus mosseae and the tomato pathogen Fusarium oxysporum f. sp. Iycopersici. Mycorrhiza 22: 189194

13. Al Raddad, Al Momany A (1987) Effect of three vesicular arbuscular mycorrhizal isolates on growth of tomato, eggplant and pepper in a field soil. Dirasat 14 161-168.

14. Kargiannidis N, Bletsos F, Stavropoulos N (2002) Effect of Verticillium wilt (Verticillium dahliae Kleb.) and mycorrhiza (Glomus mosseae) on roo colonization, growth and nutrient uptake in tomato and eggplant seedlings. Scientia Horticulture 94: 145-156.

15. Al Karaki GN (2000) Growth of mycorrhizal tomato and minerals acquisition under salt stress. Mycorrhiza 10: 51-54.

16. Al Raddad, Al Momany A (1988) Effect of vesicular arbuscular mycorrhizae on Fusarium wilt of tomato and pepper. Alexandria Journal of Agricultural Research 33: 249-261.

17. Karajeh M, Al Raddad, Al Momany A (1999) Effect of VA Mycorrhizal fungus (Glomus mosseae Gerd and Trappe) on Verticillium dahliae Kleb. Dirasat 26 338-341.

18. Caron M, Fortin JA, Richard C (1986) Effect of Glomus intraradices on infection by Fusarium oxysporum f.sp. radicis-lycopersici in tomatoes over a 12-week period. Canadian Journal of Botany 64: 552-556.

19. Caron M, Fortin JA, Richard C (1987) Effect of phosphorus concentration and Glomus intraradices on Fusarium crown and root rot of tomatoes. Phytopathology Journal 76: 942-946. 